\title{
Convert the fuel operating system as free energy operating system for agriculture implementation
}

\author{
ANISA AND GEETA
}

Received : 08.02.2017; Revised : 15.03.2017; Accepted : 23.03.2017

See end of the Paper for authors' affiliation

Correspondence to :

\section{ANISA}

Department of Farm Machinery and Power

Engineering, Vaugh School of Agricultural Engineering and

Technology, Sam

Higginbottom Institute of

Agriculture, ALLAHABAD

(U.P.) INDIA

Email : anisa0987@

gmail.com
- ABSTRACT : Based on the experimentation, it is found in this project that the Solar panel provides 17V, 1A during day time between 9.30 AM to $4.30 \mathrm{PM}$. Since the pesticide sprayers are used in this duration, testing is as carried out in this time. The $12 \mathrm{~V}, 8 \mathrm{Ah}$ battery can be charged fully in 7 hours during this time at 1.3A. Hence, this module can be operated to spray continuously 7 to 8 hour which is not possible with electrical pesticide sprayer. The model cost will not exceed Rs. 7000. Hence, the proposed model is cost effective and compatible with other models available commercially.

- KEY WORDS : Sprayer, Solar sprayer, Energy alternate devices, Free energy sprayer, Hand sprayer

— HOW TO CITE THIS PAPER : Anisa and Geeta (2017). Convert the fuel operating system as free energy operating system for agriculture implementation. Internat. J. Agric. Engg., 10(1) : 124-129, DOI: 10.15740/ HAS/IJAE/10.1/124-129. 